\title{
IMAGEM CORPORAL E SATISFAÇÃO NO TRABALHO ENTRE ADULTOS EM REABILITAÇÃO DE QUEIMADURAS
}

Maria Cristina Silva Costa $^{1}$, Lídia Aparecida Rossi² ${ }^{2}$ Rosana Aparecida Spadoti Dantas ${ }^{2}$, Larissa Ferreira Trigueros ${ }^{3}$

\begin{abstract}
RESUMO: Este estudo objetiva identificar e analisar significados atribuídos ao corpo por adultos em reabilitação de queimaduras, focalizando imagem corporal e satisfação no trabalho. Mediante justaposição de abordagens, combina e compara os resultados de duas pesquisas com um grupo de pacientes queimados. A pesquisa de abordagem qualitativa (etnografia) interpretou sentidos de qualidade de vida; a quantitativa mediu a qualidade de vida (adaptação cultural e aplicação da Burn Specific Health Scale - Revised). Os resultados indicam convergências e divergências entre achados das pesquisas analisadas quanto à valorização estética e funcional do corpo. Na pesquisa qualitativa, as cicatrizes revertem em autoimagem corporal negativa e a incapacidade de trabalho compromete a qualidade de vida; na quantitativa o impacto da queimadura sobre a imagem corporal é minimizado. Conclui-se que a primeira abordagem possibilitou aprofundar o acesso aos significados do corpo nos itens avaliados e que a utilização das duas abordagens em perspectiva complementar enriquece o conhecimento.
\end{abstract}

PALAVRAS-CHAVE: Queimaduras; Imagem corporal; Satisfação no emprego; Reabilitação.

\section{BODY IMAGE AND WORK SATISFACTION AMONG ADULTS ON BURN REHABILITATION}

\begin{abstract}
This study aims to identify and analyze the meanings regarding the body of adults on burn rehabilitation with a focus on body image and work satisfaction. By juxtaposing approaches, in this study we've combined and compared the results of two researches with a group of burned patients. The research of qualitative approach (ethnography) interpreted meanings of quality of life; the quantitative one measured the quality of life (cultural adaptation and application of the Burn Specific Health Scale - Revised). Results indicate similarities and differences between findings from the analyzed studies, regarding the body aesthetic and functional valorization. In the qualitative research, scars become a negative body self-image and the inability to work compromises the quality of life. In the quantitative research, the burn impact on the body image is minimized. It's concluded that the first approach allows further access to the meanings of the body in the evaluated items and that the use of both approaches on a complementary perspective enriches the body of knowledge.
\end{abstract}

KEYWORDS: Burns; Body image; Job satisfaction; Rehabilitation.

\section{IMAGEN CORPORAL Y SATISFACCIÓN EN EL TRABAJO ENTRE ADULTOS EN REHABILITACIÓN DE QUEMADURAS}

RESUMEN: Este estudio objetiva identificar y analizar significados atribuidos al cuerpo por adultos en rehabilitación de quemaduras, enfocando imagen corporal y satisfacción en el trabajo. Mediante yuxtaposición de abordajes, combina y compara los resultados de dos investigaciones con un grupo de pacientes quemados. La investigación de abordaje cualitativo (etnografía) interpretó sentidos de calidad de vida; la cuantitativa midió la calidad de vida (adaptación cultural y aplicación de la burn specific health scale - revised). Los resultados indican convergencias y divergencias entre hallados de las investigaciones analizadas cuanto a la valorización estética y funcional del cuerpo. En la investigación cualitativa, las cicatrices revierten en autoimagen corporal negativa y la incapacidad de trabajo compromete la calidad de vida; en la cuantitativa el impacto de la quemadura sobre la imagen corporal es minimizado. Conclúyese que el primer abordaje posibilitó profundizar el acceso a los significados del cuerpo en los ítems evaluados y que la utilización de los dos abordajes en perspectiva complementar enriquece el conocimiento.

PALABRAS CLAVE: Quemaduras; Imagen corporal; Satisfacción en el empleo; Rehabilitación.

${ }^{1}$ Antropóloga. Doutora em Antropologia Social. Docente do Departamento de Enfermagem Psiquiátrica e Ciências Humanas da Escola de Enfermagem de Ribeirão Preto da Universidade de São Paulo-EERP-USP.

${ }^{2}$ Enfermeira. Livre docente em Enfermagem. Professora Associada do Departamento de Enfermagem Geral e Especializada da EERP-USP. ${ }^{3}$ Enfermeira. Bolsista PIBIC/CNPq EERP-USP.

Autor correspondente:

Maria Cristina Silva Costa

Escola de Enfermagem de Ribeirão Preto

Rua Ayrton Roxo, 182 - 14025-270 - Ribeirão Preto-SP, Brasil

Recebido: 30/10/09

E-mail: mccosta@eerp.usp.br

Aprovado: 31/03/10 


\section{INTRODUÇÃO}

As queimaduras graves muitas vezes resultam em agravos duradouros ou permanentes à saúde, perda ou redução de capacidade funcional, sequelas físicas e estéticas e podem reverter em danos psicológicos. Configuram-se, pelos comprometimentos envolvidos, como uma condição crônica de saúde e exigem assistência específica para a reabilitação.

Avanços da medicina contribuíram para que, atualmente, a chance de sobrevivência de um paciente com até $80 \%$ do corpo queimado seja de $50 \%{ }^{(1-2)}$. Porém, apesar de sobreviverem, muitos desses indivíduos devem conviver durante o resto de suas vidas com as consequências da queimadura, que incluem sequelas diversas ${ }^{(3)}$.

Frequentemente, as queimaduras acarretam danos físicos, afetando habilidades e capacidade funcional dos indivíduos para a realização de tarefas ${ }^{(2,4)}$. Queimaduras podem provocar, ainda, prejuízos emocionais, expressados por sentimentos de depressão, negação, medo, ansiedade, bem como comprometimentos da autonomia e da imagem corporal ${ }^{(5-6)}$.

O enfoque médico e quantitativo predomina nas investigações sobre o tema que se concentram, sobretudo, em estudos epidemiológicos e na mensuração de inabilidades e/ou qualidade de vida de pacientes queimados. Muitas dessas pesquisas focalizam o retorno ao trabalho e a relação entre trabalho e qualidade de vida, identificando limitações funcionais decorrentes da queimadura ${ }^{(2,4)}$. Poucos são os estudos que abordam a imagem corporal ou as repercussões psicológicas e sociais das sequelas da queimadura ${ }^{(5-7)}$.

A literatura destaca os graves problemas enfrentados pelo paciente queimado: sofre perda de líquidos, fica suscetível a infecções, com risco de complicações pulmonares e cardiovasculares; está sujeito à dor, que acompanha os procedimentos envolvidos no cuidado, como banho e curativo ${ }^{(3,5,8)}$. A dor é tanto física, provocada pelos procedimentos e processos fisiológicos relacionados à lesão do tecido e sua cicatrização, quanto psíquica, advinda das mudanças corporais, do afastamento da família e do trabalho, entre outros ${ }^{(8-9)}$.

Ainda hospitalizado, o paciente já se preocupa com as sequelas da queimadura, e seus familiares, parceiros importantes no processo de reabilitação, também demonstram preocupação, além de apresentarem sinais de ansiedade, depressão, culpa e medo ${ }^{(6,9-10)}$.

Visando contribuir para a compreensão do problema e subsidiar ações voltadas à reabilitação de quei- maduras, o presente estudo objetiva identificar e analisar significados do corpo em pacientes queimados, destacando a imagem corporal e a satisfação no trabalho.

\section{METODOLOGIA}

Esta pesquisa, desenvolvida em Ribeirão Preto, Estado de São Paulo, durante o ano de 2008, partiu de dados coletados em dois estudos do Grupo de Investigação em Reabilitação e Qualidade de Vida (GIRQ), da Escola de Enfermagem de Ribeirão Preto da Universidade de São Paulo (EERP-USP). Esses estudos, assim como o que resultou neste artigo, integram o Projeto Temático FAPESP "O processo de reabilitação e suas interfaces com a qualidade de vida e cultura dos indivíduos" (2004-2008), aprovado pelo Comitê de Ética do Hospital das Clínicas da Faculdade de Medicina de Ribeirão Preto/USP, com o Processo HCRP n. 8830/2002.

As pesquisas analisadas intitulam-se: "Tradução para o português e validação do instrumento Burn Specific Health Scale - Revised em uma amostra de pacientes queimados" e "A produção dos sentidos de qualidade de vida por pessoas em processo de reabilitação de queimaduras”. Estas pesquisas foram desenvolvidas em Ribeirão Preto, entre 2005 e 2007.

$\mathrm{O}$ estudo que originou este artigo recorre ao método de triangulação analítica por justaposição de abordagens $^{(12)}$, numa perspectiva que visa combinar e comparar dados obtidos de maneira qualitativa com outros quantitativos. Pretende, com isso, ampliar as possibilidades de compreensão/explicação do fenômeno e contribuir para o necessário diálogo entre a abordagem qualitativa e a quantitativa.

Este estudo contou com o consentimento dos responsáveis pelas pesquisas, cujos resultados são justapostos, e acesso ao banco de dados.

A pesquisa quantitativa ${ }^{(1)}$ consistiu em uma adaptação cultural para a língua portuguesa e validação da escala denominada Burn Specific Health Scale Revised (BSHS-R), elaborada em 1994(13). Construída para avaliar a qualidade de vida relacionada à saúde em pacientes queimados, a escala é composta de 31 itens divididos em seis domínios: (1) habilidades para funções simples; (2) sensibilidade da pele; (3) tratamento; (4) afeto/imagem corporal; (5) trabalho; (6) relações interpessoais. A avaliação da qualidade de vida em cada domínio é feita mediante a soma dos valores das respostas ("Não me descreve"; "Descreve-me 
muito pouco"; "Descreve-me mais ou menos"; "Descreve-me bem"; "Descreve-me muito bem”), que variam de um a cinco; os maiores valores implicam em melhor qualidade de vida relacionada à saúde no respectivo domínio. Os critérios de inclusão dos sujeitos foram: pessoas que estiveram internadas no Hospital das Clínicas da Faculdade de Medicina de Ribeirão Preto, Universidade de São Paulo, e estavam em processo de recuperação de queimaduras graves, com idade superior a 18 anos, sem distinção de sexo, estado civil ou escolaridade ${ }^{(1)}$. Com tais critérios, selecionaramse 82 sujeitos.

A pesquisa qualitativa ${ }^{(11)}$ objetivou interpretar sentidos de qualidade de vida em vítimas de queimadura. Recorreu ao método etnográfico - fundamentado teoricamente na Antropologia Interpretativa - e às técnicas de observação direta e entrevistas semiestruturadas (gravadas e posteriormente transcritas). No processo de análise identificaram-se as convergências e divergências entre os dados, para agrupá-los em unidades de significados; por fim, a análise convergiu para a compreensão interpretativa desses significados, por meio de sua inserção em um dado contexto cultural. A pesquisa etnográfica elegeu como critério de inclusão: pessoas que tivessem participado da pesquisa quantitativa mencionada (adaptação da Burn Specific Health Scale - Revised) ${ }^{(11)}$. Foram sorteados 20 entre os 82 participantes da primeira pesquisa, tendo 19 concordado em participar.

A justaposição de abordagens baseou-se nos resultados da aplicação da escala e nas entrevistas da pesquisa etnográfica (novamente analisadas no presente estudo), de maneira a apreender significados do corpo, após a queimadura, com o enfoque direcionado à imagem corporal e satisfação no trabalho. Estes aspectos foram priorizados porque se destacam como os mais relevantes nas entrevistas e estão presentes nos itens da escala.

\section{RESULTADOS}

Participaram do estudo de adaptação da escala BSHS-R 82 sujeitos com idades entre 18 e 78 anos, sendo a maioria do sexo masculino (68,3\%), casada $(63,4 \%)$ e com baixa escolaridade (47,6\% possuem o primeiro grau incompleto ou são analfabetos) ${ }^{(1)}$. Todos apresentavam sequelas de queimadura: 53 (64,6\%) tinham sequelas estéticas e funcionais, 28 (34,2\%) sequelas estéticas, e um participante $(1,2 \%)$ apresentava apenas sequelas funcionais. Os principais agentes etiológicos da queimadura foram: álcool (31,4\% dos participantes), líquidos quentes (19,5\%), eletricidade (11\%) e chamas $(9,8 \%)^{(1)}$.

Entre os 19 participantes do estudo etnográfico (idades entre 18 e 50 anos, 12 homens e 7 mulheres, a maioria casada e todos incluídos no primeiro estudo); 11 (57,9\%) tinham sequelas estéticas e 8 (42,1\%) sequelas funcionais e estéticas; quanto aos principais agentes etiológicos: líquidos quentes (42,1\%), álcool $(21,0 \%)$ e chamas $(15,7 \%)^{(11)}$.

Os agentes causadores da queimadura costumam ser classificados em: químicos (ácidos ou bases), térmicos (inflamáveis, líquidos ou metais superaquecidos, brasas e chama direta) e elétricos (corrente elétrica) ${ }^{(3)}$. Portanto, entre os sujeitos das pesquisas comparadas, os agentes térmicos constituíram a principal causa da queimadura*.

As respostas dos 82 participantes aos quatro itens do domínio 5 (trabalho) da BSHS-R mostraram que as opções mais frequentemente escolhidas foram "Descreve-me muito pouco" e "Não me descreve". Por exemplo, para o item "Voltar ao trabalho, fazendo suas tarefas como antes”, a distribuição das respostas foi: 25,6\% para "Não me descreve"; 23,2\% "Descreveme bem"; 22\% "Descreve-me muito pouco"; 19,5\% "Descreve-me mais ou menos"; e 9,8\% "Descreveme muito bem". Os itens "Minha queimadura tem causado problemas para eu fazer minhas tarefas no meu trabalho e em casa" e "A queimadura afetou minha capacidade para trabalhar" tiveram mais de $50 \%$ das respostas para as opções "Não me descreve" e "Descreve-me muito pouco"(1).

Constata-se, por conseguinte, que as sequelas da queimadura afetaram de algum modo a continuidade do trabalho antes realizado, sem impedir a maioria dos participantes de trabalhar. Todavia, muitos precisaram assumir atividades que exigiam habilidades diferentes daquelas mobilizadas por sua antiga função.

Resultados pouco diversos foram encontrados pela pesquisa etnográfica: 7 (36,8\%) haviam retornado ao trabalho sem dificuldades, 4 (21\%) retornaram exercendo funções diferentes, 6 (31,6\%) não retornaram ao trabalho, 1 (5,3\%) estava aposentado e 1 (5,3\%) desempregado (sem relação com a queimadura) ${ }^{(12)}$. Dentre os que não voltaram a trabalhar, a queimadura foi apontada como causa da incapacidade para o trabalho, quer pelos cuidados especiais requeridos, quer

*Resultados de pesquisas internacionais e brasileiras (regionais) apontam agentes elétricos (48\%) e térmicos (43,5\%) como os causadores mais frequentes dos acidentes ocorridos com adultos ${ }^{(4)}$ 
pela diminuição ou perda de capacidade funcional:

Eu fui obrigado a parar, porque meu trabalho é um trabalho de campo, roça. Então, eu não poderia facilitar com essa queimadura, ficar aguentando muito sol, terra, poeira [...]. (E5)

Pelos dados etnográficos, verifica-se que a condição de saúde dos sujeitos com sequelas funcionais e estéticas reflete em maior prejuízo da capacidade de trabalhar do que a dos demais (sequelas estéticas) e exige o enfrentamento do sentimento de invalidez. Nos registros das pesquisas analisadas, as queimaduras nos membros inferiores ou superiores são as que mais repercutem em impedimentos ao trabalho. As entrevistas dos sujeitos com este tipo de queimadura revelam que a concebem como marco que separa vida produtiva e não produtiva:

[...] eu sempre no intuito de querer voltar, de não me sentir um inválido, que eu ia ser uma pessoa que ia ter um monte de limitações, mas que eu ia ser produtivo. (E2)

Depreende-se, das avaliações registradas nas entrevistas, que o valor do indivíduo perante a sociedade vincula-se à sua capacidade de trabalhar, da qual depende também a realização pessoal, prejudicada, em vários deles, pelas consequências da queimadura:

Eu me considero uma pessoa bem sucedida, pelo seguinte: eu tenho meu trabalho. (E11)

[...] realizado, realizado eu não sou né, eu não estou trabalhando. (E18)

Um aspecto importante relacionado ao trabalho, verificado na pesquisa etnográfica e não contemplado na aplicação da escala, é a dimensão de gênero. Pelos depoimentos, apreende-se que a sequela funcional da queimadura atinge, no homem, além da capacidade de trabalho, seu papel na hierarquia familiar, assimilado, predominantemente, como o de provedor:

[...] eu tenho dois filhos pra cuidar, a minha esposa e eu, como se diz, dependendo totalmente das minhas mãos. (E2)

As mulheres, por sua vez, ressaltam as dificuldades para realizar tarefas domésticas, papel tradicio- nalmente atribuído à mulher, em nossa sociedade:

[...] só acho ruim que eu não posso usar sabão, sabão nenhum, porque irrita. Eu preciso esperar alguém lavar para mim. Eu sou só dona de casa. (E9)

Os resultados da aplicação da escala relativos à realização das tarefas cotidianas demonstram que $50 \%$ dos participantes apresentaram "Nenhuma Dificuldade" nas tarefas simples (amarrar sapatos, sentar, vestir-se, banhar-se). Da mesma forma, as entrevistas etnográficas não identificam dificuldades para essas tarefas; porém, um dos participantes relata despender mais tempo com autocuidado:

Agora eu levanto de manhã, eu levo mais ou menos uma hora pra tomar banho e passar creme; antes do acidente, com vinte minutos estava dentro do meu serviço. (E14)

A imagem corporal é avaliada pela BSHS-R ${ }^{(13)}$, no domínio 4 (afeto/imagem corporal), com 8 itens que abordam sentimentos de tristeza ("Eu me sinto triste e deprimido com frequência”) e solidão ("Eu fico chateado com o sentimento de solidão"), problemas com a aparência das cicatrizes ("A aparência das minhas cicatrizes me incomoda") e pessoal ("Minha aparência me incomoda muito"). No estudo analisado, entre 31,7\% e $64,6 \%$ dos participantes responderam aos itens com a opção "Não me descreve". Na interpretação dos autores, os resultados demonstram que problemas relacionados à aparência pessoal, bem como sentimentos de tristeza e solidão, não eram percebidos no grupo estudado.

Resultados bastante diversos foram encontrados na pesquisa etnográfica, no que diz respeito à imagem corporal. Entre 19 sujeitos, 10 relatam sentir algum incômodo com relação à cicatriz, seja pelos olhares curiosos dos outros, seja pela própria aparência da marca:

Desconforto assim, porque se vou fazer uma ginástica, se eu vou fazer uma hidroginástica, todo mundo fica perguntando. (E6)

Quase todos os participantes da pesquisa etnográfica revelam seus esforços para ocultar as cicatrizes com o uso de roupas fechadas, ou isolando-se:

[...] se eu não ponho uma calça comprida eu não saio de casa. Procuro esconder. A mão eu não ligo, 
mas as pernas, eu procuro esconder. (E7)

Eu tinha que colocar blusa de manga porque eu sentia vergonha de sair com aquela cicatriz horrorosa no braço. (E13)

Vários entrevistados demonstram sofrimento ante a reação do círculo de amigos e revelam o forte abalo que sofre a autoimagem corporal:

Às vezes, a gente fica limitado a algumas coisas [...] você quer participar. Às vezes, a gente vai numa festa, vê todo mundo lá, de short [...] é um pouco constrangedor você ficar, você não tem um corpo bonito, você não tem mais. (E3)

Os outros ficam com vergonha perto de mim. Os meus amigos, alguns têm vergonha [...]. Muitos não falam nada, mas só de ver você percebe. (E16)

A pesquisa etnográfica enfatiza os prejuízos que as sequelas visíveis da queimadura trazem para o modo como os participantes se vêem. Estes indicam a assimilação de uma nova percepção do corpo marcada por sentimentos de tristeza e vergonha e a concepção das marcas como deformação, condição indesejável ante a qual só lhes resta acostumar-se:

[...] eu fiquei deformado, algumas partes do meu corpo ficaram com aspecto mais feio; tudo bem [...] vou ter que conviver com isso pro resto da minha vida. (E12)

\section{DISCUSSÃO}

Além da natureza biológica do corpo humano, que estabelece uma igualdade fundamental de todos os homens, o corpo é objeto apropriado e modelado pela sociedade, sendo impossível estabelecer uma rígida distinção entre o que diz respeito à natureza e aquilo que é da ordem sociocultural ${ }^{(14)}$. Representado e passível de leituras de acordo com o contexto cultural, o corpo humano não pode ser pensado de maneira dissociada de condição social, identidade grupal e expectativas sociais, porque se insere em um sistema social e simbólico, sobre ele incidindo determinadas demandas e significados socialmente elaborados ${ }^{(14-15)}$.

As entrevistas refletem algumas dessas demandas sociais, quando sobrecarregam de significados a capacidade de trabalhar, priorizada como condição essencial da recuperação da normalidade. O retorno ao trabalho foi mencionado por todos os sujeitos da pesquisa etnográfica ao avaliarem a qualidade de vida após a queimadura, e dez participantes destacaram transformações no trabalho, porque mudaram de função e precisaram adaptar-se às novas atribuições, ou mesmo porque não voltaram a trabalhar. Pelos resultados da aplicação da escala, igualmente constata-se que, no processo de reabilitação, a maioria dos queimados voltou a trabalhar, mas em função diferente. Pesquisa sueca também indica mudanças significativas na retomada do trabalho, pois entre os participantes de estudo, 30\% tinham melhor emprego que antes da queimadura; $62 \%$ continuaram com a mesma função, porém apresentando dificuldade e $8 \%$ estavam em emprego pior ou que exige menor habilidade ${ }^{(16)}$.

Relacionando o tempo de retorno ao trabalho com a superfície corporal queimada (SCQ) e a extensão da queimadura, pesquisa realizada na Finlândia concluiu que quanto maior a SCQ maior será o tempo para o retorno ao trabalho (um mês a dois anos); quanto mais profunda a queimadura for, maior o tempo necessário para o retorno ao trabalho (seis meses a um ano) ${ }^{(17)}$. Queimaduras nas mãos e na face repercutem da mesma forma no retorno ao trabalho ${ }^{(2)}$, sendo aquelas que atingem os membros as mais comprometedoras da habilidade dos indivíduos para executar determinadas tarefas ${ }^{(17)}$, o que se observa nos sujeitos das pesquisas analisadas. Os resultados das pesquisas aqui justapostas $^{(1,11)}$ e a literatura especializada ${ }^{(2,4,16-17)}$ indicam que gravidade, extensão e localização da queimadura afetam diferentemente a capacidade para trabalhar e o tempo necessário para o retorno ao trabalho.

Apesar das semelhanças entre os resultados da pesquisa etnográfica e da aplicação da escala (também de estudos relatados na literatura) referentes a retorno ao trabalho, as entrevistas indicam a atribuição de valor essencial à capacidade de trabalhar, implicando uma concepção do corpo que o submete à inserção no universo do trabalho, e outros significados correlatos não abordados pelos itens da escala.

Os depoimentos dos sujeitos coincidem com achados de pesquisas segundo as quais, para o indivíduo queimado, é crucial o restabelecimento das condições de saúde anteriores à queimadura, com ênfase na reabilitação funcional para o trabalho ${ }^{(2,16)}$. Porém, mais do que isso, nas reflexões estimuladas pela entrevista etnográfica, é possível perceber a expressão de noção corrente nas sociedades industriais, que subordina o corpo à capacidade para trabalhar. Construída como norma 
para a definição de saúde, normalidade e integração social, a capacidade de trabalho torna-se condição e signo de realização e sucesso pessoal ${ }^{(15)}$. Os entrevistados corroboram, assim, a compreensão de que, sob os imperativos econômicos das sociedades industriais, o corpo é concebido como instrumento de trabalho ${ }^{(15,18)}$.

Os resultados dos dois estudos, ao demonstrarem a importância atribuída ao trabalho, indicam a necessidade de ações direcionadas aos queimados que visem à reabilitação para o trabalho, assim como de implementação de trabalho assistencial coordenado. A conjugação das ações tornaria possível levar em conta as necessidades especiais dos indivíduos com sequelas de queimaduras e ampliar suas possibilidades de inserção no mercado de trabalho.

Quanto à imagem corporal, as respostas aos itens da escala não permitem constatar a existência de autoimagem negativa em razão das mudanças na aparência desencadeadas pela queimadura. Diferentemente, os resultados da pesquisa etnográfica deixam clara a elaboração de uma imagem corporal depreciativa por quem apresenta extensas marcas de queimaduras. As cicatrizes são avaliadas como deformações que separam 10 dos 19 entrevistados daquilo que concebem como condição de normalidade e ideal de beleza.

O corpo humano está sujeito, em todas as sociedades, às demandas estéticas, além das demandas relativas ao trabalho. Nas sociedades ocidentais contemporâneas, a beleza corporal é associada à perfeição simetria, juventude, esbelteza, entre outros atributos, transformando-se em signo de desigualdade tudo aquilo que afasta os indivíduos disso ${ }^{(14)}$, como as extensas cicatrizes, que impactam negativamente a autoestima ${ }^{(6)}$.

A boa aparência, aquela que se coaduna com os padrões culturais, associa-se, nas sociedades contemporâneas, a sucesso pessoal e ascensão social, fato reforçado pela mídia, cujos incentivos para avaliar a aparência e corrigir as falhas em busca da perfeição são frequentes ${ }^{(14)}$. Ao lado de um verdadeiro culto ao corpo, que estimula homens e mulheres a se remodelarem para atender às demandas estéticas ${ }^{(14,19)}$, evidenciase seu desnudamento, com a expansão da exposição pública do corpo, em nossa sociedade ${ }^{(19)}$.

Situados diante desses padrões, os participantes da pesquisa etnográfica passam por transformações na maneira como veem a si mesmos perante os outros. Voltar ao convívio social, após a hospitalização, significa relacionar-se com um universo onde suas cicatrizes e incapacidades são alvo de curiosidade ${ }^{(7)}$, quando não de rejeição e fontes de sofrimento ${ }^{(10)}$.

A marca da queimadura transforma-se em estigma - referência a um atributo muito depreciativo ${ }^{(20)}$ que diferencia negativamente seu portador em relação ao grupo. No caso dos que sofreram graves queimaduras, a cicatriz (estigma) é vista como signo da degradação sofrida, característica que os afasta da normalida$\mathrm{de}^{(17)}$. O corpo, representado nas sociedades contemporâneas como realidade em si - pela qual o indivíduo se apresenta a outros e a sociedade avalia a qualidade do ser - transforma-se em símbolo de não pertinência social $^{(14)}$.

Como os seres humanos constroem a identidade pessoal e elaboram a autoimagem num processo relacional muito influenciado pela forma como os outros os vêem, compreende-se a tentativa de esconder as cicatrizes das queimaduras, segundo as narrativas dos participantes da pesquisa etnográfica e diversos estudos sobre queimados ${ }^{(5,11,17)}$. Quanto mais visível e extensa a queimadura, maiores são os sentimentos negativos em relação à imagem corporal $^{(5)}$, que acarretam sofrimento psíquico e demandam atenção especializada na reabilitação.

\section{CONSIDERAÇÕES FINAIS}

Ao combinar e comparar os resultados de uma pesquisa etnográfica com aqueles obtidos em investigação com aplicação de escala - ambas conduzidas por membros de um mesmo grupo de pesquisa evidenciam-se convergências e divergências. Embora se observem semelhanças nos dados relativos ao retorno ao trabalho após a queimadura, constata-se que as respostas aos itens da BSHS-R não refletem plenamente os achados da abordagem qualitativa: minimizam o impacto da queimadura na aparência e não contemplam a avaliação da relevância do trabalho na vida dos sujeitos.

As diversidades encontradas nos resultados das pesquisas certamente se relacionam com as técnicas e instrumentos utilizados. Enquanto a escala trabalha com um instrumento totalmente estruturado, com alternativas limitadas para as respostas, as entrevistas etnográficas, com questões abertas, possibilitam aos participantes a expressão mais completa de seus sentimentos, experiências, motivações e valores.

A insatisfação relativa ao trabalho, indicada por respostas a alguns itens do instrumento, revela-se, principalmente e de maneira muito mais categórica, nas entrevistas etnográficas, em que se ressalta a 
estreita vinculação entre corpo, trabalho e normalidade. Esses resultados orientam para a inclusão de ações assistenciais voltadas à reabilitação para o trabalho.

No que diz respeito à imagem corporal, na pesquisa quantitativa encontram-se poucos aspectos negativos dos indivíduos com relação à sua aparência ou de suas cicatrizes. Porém, ao terem uma abordagem mais reflexiva, os participantes acabam contradizendo respostas fornecidas anteriormente. O estudo etnográfico evidencia o desconforto dos participantes com a aparência de suas cicatrizes no convívio social, bem como sua preocupação em escondê-las.

Objeto por meio do qual o indivíduo se apresenta a outros de determinado grupo e à sociedade como um todo, o corpo modificado pela queimadura passa a ser avaliado de maneira negativa, torna-se obstáculo à reabilitação social e fonte de sofrimento psíquico. Sob este aspecto, os resultados do estudo etnográfico indicam a necessidade de assistência especializada em saúde mental, de maneira a oferecer suporte psicológico para o enfrentamento dos danos à imagem corporal provocados pelas sequelas da queimadura.

A comparação dos dados das duas investigações sugere que a pesquisa etnográfica instigou nos participantes reflexões que asseguraram, de maneira mais reveladora que a escala, o acesso aos significados do corpo vitimado por queimaduras graves, quanto à imagem corporal e à satisfação no trabalho, aspectos focalizados neste estudo. A articulação analítica dos dados indica a importância de utilizar as duas abordagens em perspectiva complementar.

\section{REFERÊNCIAS}

1. Ferreira E. Adaptação cultural da "Burn Specific Health Scale - Revised” (BSHS-R) versão para brasileiros que sofreram queimaduras [dissertação]. Ribeirão Preto (SP): Universidade de São Paulo; 2006.

2. Tantulla K, Vuola J, Asko-Seljavaara S. Return to employment after burn. Burns. 1997;23(4):341-4.

3. Rossi LA, Garcia TR, Chianca TM, Barrufini RCP. Queimaduras: características dos casos tratados em um hospital escola em Ribeirão Preto (SP), Brasil. Rev Panam Salud Pública. 1998;4(6):401-4.

4. Noble J, Gomez M, Fish JS. Quality of life and return to work following electrical burns. Burns. 2006;32(2):15964.

5. Pope SJ, Solomons WR, Done DJ, Cohn N, Possamai
AM. Body image, mood and quality of life in young burn survivors. Burns. 2007;33(6):747-55.

6. Patridge J, Robinson E. Psychological and social aspects of burns. Burns.1995;21(5):453-7.

7. Bergamasco EC, Rossi LA, Amâncio ACG, Carvalho EC. Body image of patients with burn sequellae: evaluation through the critical technique. Burns. 2002;28(1):47-52.

8. Carlucci VDS, Rossi LA, Ficher AMFT, Ferreira E, Carvalho EC. A experiência da queimadura na perspectiva do paciente. Rev Esc Enferm USP. 2007;41(1):21-8.

9. Rossi LA, Vila VSC, Zago MMF, Ferreira E. The stigma of burns: perceptions of burned patients' relatives when facing discharge from hospital. Burns. 2005;31(1):3744.

10. Rossi LA, Costa MCS, Dantas RS, Ciofi-Silva C, Lopes LM. Cultural meaning of quality of life: perspectives of brazilian burn patients. Disabil Rehabil. 2009;31(9):7129.

11. Costa MCS, Rossi LA, Lopes LM, Cioffi CL. Significados de qualidade de vida: análise interpretativa baseada na experiência de pessoas em processo de reabilitação de queimaduras. Rev Latino-Am Enfermagem. 2008; 16(2):252-9.

12. Deslandes SF, Assis SG. Abordagens quantitativa e qualitativa em saúde: o diálogo das diferenças. In: Minayo MCS, Deslandes SF, organizadoras. Caminhos do pensamento: epistemiologia e método. Rio de Janeiro: Fiocruz; 2003. p.195-223.

13. Blalock SJ, Bunker BJ, De Vellis RF. Measuring health status among survivors of burn injury: revisions of the burn specific health scale. J Trauma. 1994;36(4):508-15.

14. LeBreton D. Adeus ao corpo: antropologia e sociedade. Campinas: Papirus; 2003.

15. Canguillhem G. O normal e o patológico. Rio de Janeiro: Forense Universitária; 2002.

16. Dyster-Aas J, Kildal M, Willebrand M. Work status and burn specific health after work-related burn injury. Burns. 2004;30(1):839-42.

17. Rumsey N, Harcourt D. Body image and disfigurement: issues and interventions. Body Image. 2004;1(1):83-97.

18. Spiller APM, Dyniewicz AM, Slomp MG. Qualidade de vida de profissionais da saúde em hospital universitário. 
Cogitare Enferm. 2008;13(1):88-95.

19. Bueno ML, Castro AL. Corpo território da cultura. São Paulo: Annablume; 2005.

20. Goffman E. O estigma: notas sobre a manipulação da identidade deteriorada. Rio de Janeiro: Guanabara Koogan; 1988. 